\title{
Elemental diets in treatment of acute Crohn's disease
}

\author{
C O'MORAIN, A W SEGAL, A J LEVI
}

\section{Summary and conclusions}

Twenty-seven patients with 32 acute exacerbations of Crohn's disease were treated for four weeks with an elemental diet. At the end of treatment 29 of the exacerbations had remitted both clinically and biochemically. After six months six patients had relapsed.

These findings suggest that the elemental diet is effective in treating acute Crohn's disease, but the reasons are not clear. The diet may be effective because it provides nutritional support, is hypoallergenic, acts as a medical bypass from the affected area, or alters bowel flora. The patient's general wellbeing is improved by the supply of adequate energy and essential foodstuffs in a form easily available without further digestion and given in a safe, simple, non-toxic way.

\section{Introduction}

No generally accepted regimen exists for the treatment of acute exacerbations of Crohn's disease. Many different treatments are used including antibiotics, azathioprine, sulphasalazine, and steroids, often without controlled trials to support their efficacy. Patients with Crohn's disease often have a negative nitrogen balance as a result of anorexia and reduced protein intake, diminished absorption by the small intestine, losses by exudation from inflamed mucosa, and systemic effects of chronic inflammation. Total parenteral nutrition ${ }^{1-4}$ and elemental diets $^{5-11}$ have been used in an attempt to reverse this metabolic imbalance before operative intervention (see also $P$ Milewski and M Irving (abstract D6), J C Paris et al (abstract L77), and M J Hall and R I Russell (abstract P77), European Congress on Parenteral and Enteral Nutrition, Stockholm, 2-5 September 1979). As these patients improve nutritionally the indications for operation often recede, raising the possibility that "artificial" nutrition might be useful as a primary treatment for Crohn's disease. Total parenteral nutrition requires careful monitoring, and serious complications have been reported. ${ }^{4}$ An elementaldiet regimen is safe, non-toxic, and easy to administer. In this paper we report the results of using an elemental diet in the treatment of patients with acute Crohn's disease.

\section{Patients}

We treated 32 exacerbations of Crohn's disease in 27 patients (21 men, six women) requiring admission to hospital. Seven of the patients were aged under 20,13 were aged 20-40, and seven were over 40 . Twelve patients had disease of only the small bowel, 11 of the small and large bowel, and four of only the large bowel. All exacerbations were characterised by abdominal pain that severely limited activity and by diarrhoea (three or more loose stools daily). Weight loss of over $2 \mathrm{~kg}$ occurred in the month before 20 exacerbations. Eleven exacerbations were associated with fever of over $38^{\circ} \mathrm{C}$ for a

Division of Clinical Sciences, Clinical Research Centre and Northwick Park Hospital, Harrow, Middlesex HA1 3UJ

C O'MORAIN, MB, MRCPI, honorary senior registrar

A W SEGAL, PHD, MRCP, honorary senior registrar (present appointment: senior lecturer, department of clinical haematology, University College Hospital Medical School, London WC1)

A J LEVI, MD, FRCP, consultant gastroenterologist week or more; 24 with an erythrocyte sedimentation rate of over $20 \mathrm{~mm}$ in the first hour; 20 with a haemoglobin concentration of under $12.5 \mathrm{~g} / \mathrm{dl}$ (men) or under $10.5 \mathrm{~g} / \mathrm{dl}$ (women); and 18 with a serum albumin concentration of under $35 \mathrm{~g} / \mathrm{l}$. Six young patients had growth failure, three patients had clinically evident subacute intestinal obstruction, one had an abdominal wall fistula, one presented with rectal bleeding, and four had a seronegative peripheral arthropathy.

\section{Treatment}

After initial inpatient assessment an elemental diet was begun. All food was withdrawn, except for tea and coffee without milk, boiled sweets, and clear minerals, and replaced with an elemental diet (Vivonex) supplying 209-314 kJ (50-75 kcal)/kg body weight and 8-12 g nitrogen/day. Because the reconstituted diet is hyperosmolar $(600 \mathrm{mmol}(\mathrm{mosmol}) / \mathrm{l})$ its concentration was gradually increased to full strength over three days to reduce side effects such as diarrhoea and abdominal colic. After four weeks of the elemental diet solid food was gradually reintroduced over three days. The diet was started in hospital, but the patients were allowed home once they had become accustomed to it and had shown clinical improvement (generally after seven to 14 days).

The diet was well tolerated in all of the patients except two, who were withdrawn from the study because they were unable to drink the diet owing to an aversion to its taste. A third patient was withdrawn from the trial for resection of a chronic ileal obstruction. Of the 24 patients (29 exacerbations as five patients were treated twice) who remained within the trial, eight received no other treatment; three received steroids (prednisone $30 \mathrm{mg} /$ day for two weeks reducing to a maintenance dose of $10 \mathrm{mg} /$ day); and nine received intermittent levamisole $(2 \mathrm{mg} / \mathrm{kg} /$ day for three days every 14 days $)$, which was introduced from the third week onwards. Four continued with the drugs that they had been taking when they relapsed before the trial: two were receiving maintenance doses of steroids $(<10 \mathrm{mg}$ prednisone/day) and one each azathioprine and sulphasalazine. The patients were followed up weekly for four weeks and then at monthly intervals. At each visit they were weighed and their height measured, they were asked about their symptomatology and occupational and social wellbeing, and blood samples were taken for biochemical and haematological investigations.

\section{Results}

In all 29 acute episodes in which the four-week course of the elemental diet was completed the patients showed a pronounced clinical improvement. Within two weeks abdominal pain and diarrhoea were relieved and weakness, fever, and anorexia had cleared. Figure 1 shows the effect of this treatment on the variables of disease activity. There was a dramatic and sustained improvement in all the variables monitored except for weight, which fell slightly in the first two weeks of treatment but rose to normal thereafter. There was a mean fall in erythrocyte sedimentation rate of $24 \mathrm{~mm}$ in the first hour, and an increase in serum albumin concentration of $4.3 \mathrm{~g} / 1$ and in haemoglobin concentration of $1.2 \mathrm{~g} / \mathrm{dl}$ (excluding patients who received transfusions) Figure 2 shows a typical response in a 38 -year-old man with smallbowel Crohn's disease treated solely with the elemental diet. Within one week stool frequency had fallen from eight to three times daily; by four weeks his weight had risen by $3 \mathrm{~kg}$ and his erythrocyte sedimentation rate decreased from 43 to $10 \mathrm{~mm}$ in the first hour.

One of the patients who presented with melaena and was then fed on a normal ward diet promptly bled again. He was placed on an elemental diet and had no recurrence of bleeding. One patient's enterocutaneous and enterovesical fistulae healed with the elemental diet.

Six months after treatment with the elemental diet 18 of the 24 patients remained clinically in remission. All had gained weight 
(mean $6.1 \mathrm{~kg}, \mathrm{SE} 1.3 \mathrm{~kg}$ ) and the serum albumin concentration had risen in all (mean 8.0, SE 1.76). Of the six patients who relapsed, three required bowel resection, one was treated by increasing the prednisone dosage, and two were studied again while receiving a second course of the elemental diet. Growth rate as assessed with Tanner tables ${ }^{15}$ was maintained or exceeded in six young patients (four boys, two girls) who had previously had deficient growth. Two of these had received concurrent prednisone treatment.
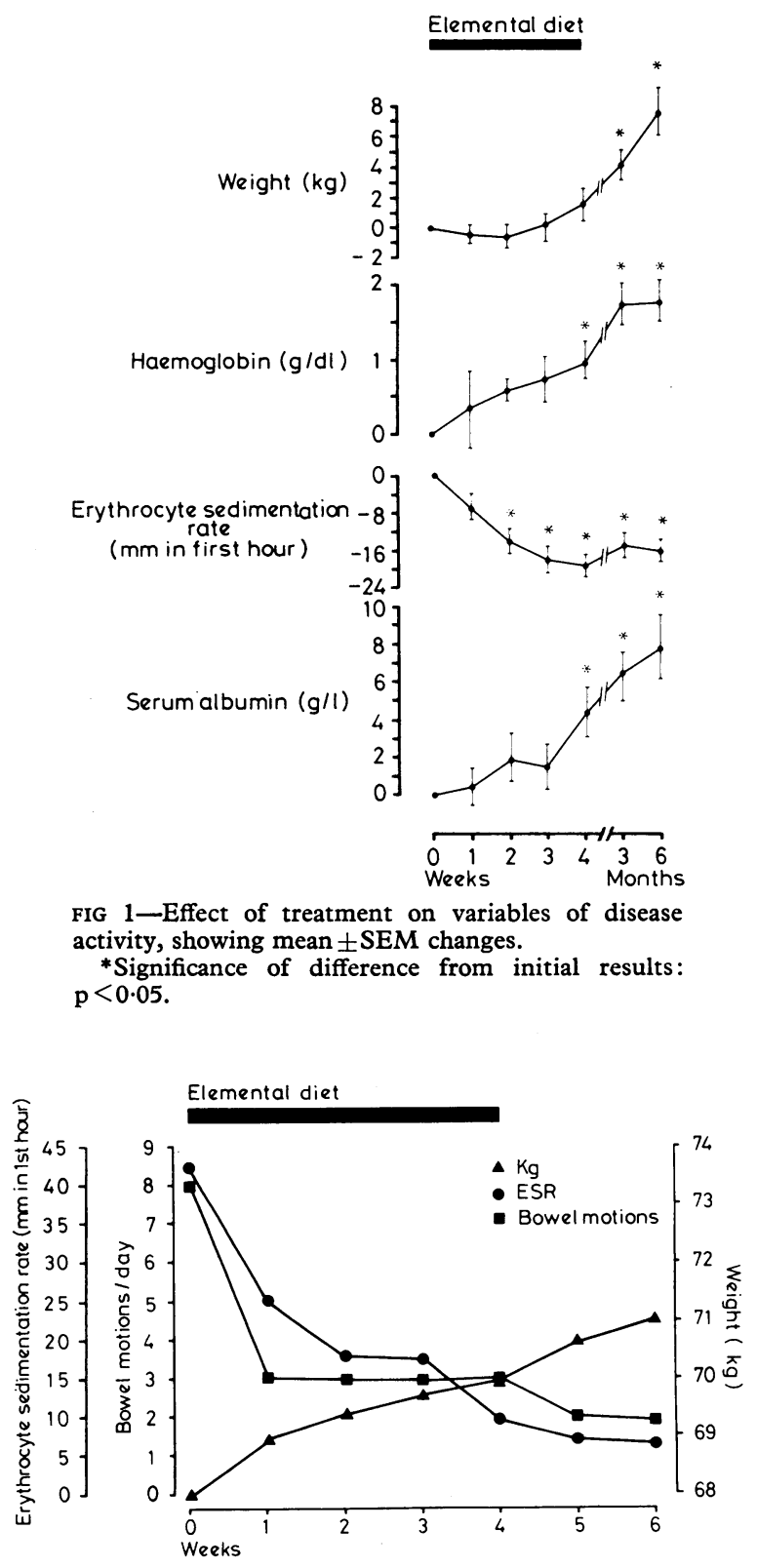

FIG 2-Effect of elemental diet on wellbeing of 38-year-old man with small-bowel Crohn's disease.

\section{Discussion}

Reports of the use of an elemental diet in Crohn's disease are few, and many of the patients treated had surgical indications for intervention. Stephens and Randall ${ }^{5}$ reported a good result with an elemental diet given postoperatively to a patient with severe Crohn's disease. Giorgini et $a l^{b}$ treated successfully a 13-year-old boy with active Crohn's disease unresponsive to other treatment. Voitk et $a l^{7}$ treated seven patients with Crohn's disease; all of their patients improved their nutritional state as evidenced by weight gain, positive nitrogen balance, and increased red cell mass. Rochio et al ${ }^{8}$ treated 25 patients with Crohn's disease with an elemental diet. Ten of their patients eventually required surgery but were able to undergo operation in a better nutritional state. Goode et $a l^{10}$ used an elemental diet successfully for long-term nutritional support in eight patients with Crohn's disease. Segal et al ${ }^{11}$ induced remission in eight patients with active uncomplicated Crohn's disease using an elemental diet as the sole initial treatment. An elemental diet was reported to have been helpful in managing 11 patients with complications of Crohn's disease such as perianal fissure, subacute obstruction, and bile-salt-induced diarrhoea (M J Hall and R I Russell, abstract P77, European Congress on Parenteral and Enteral Nutrition, Stockholm, 1979).

Our results confirm these observations that an elemental diet may be valuable as the main treatment of acute Crohn's disease. In 19 of the patients the diet was the only treatment given initially. All of the patients who completed the diet treatment were considered to be in clinical remission at four weeks. There was an initial loss of weight probably due to the low residue and the gradual build-up of energy intake. At the end of the treatment period the patients' nutritional state had improved as evidenced by the rise in serum albumin concentration and weight gain. At six months six of the patients had relapsed. Three of the patients, who had symptoms of subacute obstruction, all eventually required operations. The diet, though unpalatable, was tolerated by mouth in all but two of our patients. With encouragement patients adapt to the diet, particularly when they notice an improvement in their symptoms.

The exact mechanism by which an elemental diet induces remission of this disease is not clear. The diet may alter the course of the disease by modifying the nutritional state of the patient. Administration of a balanced diet containing adequate energy and amino-acids is likely in itself to be beneficial in any disease associated with anorexia, vomiting, diarrhoea, and resultant undernutrition. In addition the diet may have a more direct effect by supplying essential vitamins and minerals or excluding ingested toxins.

An elemental diet may be beneficial in Crohn's disease by inducing a critical change in the intestinal microflora. Some workers have found a significant increase in Gram-negative anaerobic rods and Gram-positive rods in stools from patients with Crohn's disease. ${ }^{13}$ Some reports ${ }^{14}$ suggest a dramatic reduction in microbial flora in healthy volunteers fed an elemental diet. These results were not confirmed by other workers $^{15-17}$ who used more sensitive techniques, but changes in species types were noted. Crohn's disease may be induced or perpetuated by constituents of a normal diet, possibly by an immunological mechanism. Formation of granulomas, a characteristic histological feature of Crohn's disease, may result from the persistence of luminal contents within the mucosa. ${ }^{11}$ A wide range of antibodies against dietary proteins are readily detectable in the serum. ${ }^{18}$ These antibodies may have developed against dietary proteins that may themselves be pathogenic, or cause tissue damage after the formation of immune complexes. Equally probably, however, this antibody production is a result rather than the primary cause, because foreign protein would be expected to penetrate the bowel wall through a damaged mucosa, thereby promoting a secondary immunological reaction. ${ }^{19}$ The removal of oral protein by treatment with an elemental diet may cause these patients to improve by removing either the primary cause or the offending protein responsible for secondary immune-mediated tissue damage.

Patients with Crohn's disease of the colon improve after diversion of the faecal stream. ${ }^{20}$ An elemental diet contains amino-acids, hexose sugars, essential fatty acids, minerals, and vitamins and is absorbed in the upper intestinal tract. It also reduces both pancreatic and gastric secretions. ${ }^{21}$ It may therefore act as a medical bypass by preventing the food and the secretions from gaining access to the inflammatory lesions in the bowel thereby giving them a chance to heal. The depression of gastrointestinal secretion may be important in the healing of intestinal fistulae, and elemental diets have been found useful in the treatment of fistulae. ${ }^{9}$ One of our patients had ilealvesical and enterocutaneous fistulae, which healed after 28 days on the diet. 
Thus our findings confirm that an elemental diet is an extremely useful method for inducing a remission in acute Crohn's disease, although it does not appear to protect against long-term relapse.

CO'M was the recipient of an Eton Fellowship. We are grateful to Miss P Hulme and her colleagues in the department of dietetics for their continued help in these studies.

Requests for reprints should be addressed to DrCO'Morain, Division of Clinical Sciences, Clinical Research Centre, Harrow, Middlesex HA1 3UJ.

\section{References}

1 Fischer JE, Foster GS, Abel RM, Abbott WM, Ryan JA. Hyperalimentation as primary therapy for inflammatory bowel disease. Am f Surg 1973;125:165-75.

2 Anderson DL, Boyce HW. Use of parenteral nutrition in treatment of advanced regional enteritis. Am $\mathcal{F}$ Dig Dis 1973;18:633-40.

3 Vogel CM, Corwin TR, Bane AE. Intravenous hyperalimentation in the treatment of inflammatory diseases of the bowel. Arch Surg 1974;180: 460-7.

${ }^{4}$ Reilly J, Ryan J, Strole W, Fischer J. Total parenteral nutrition and inflammatory bowel disease. Acta Chir Scand 1976;142, suppl 466:92-3.

${ }^{5}$ Stephens RV, Randall HT. Use of a concentrated balanced liquid elemental diet for nutritional management of catabolic states. Ann Surg 1969;170: 642-67.

6 Bury KD, Stephens RV, Randall HT. Use of a chemically defined, liquid elemental diet for nutritional management of fistulas of the alimentary tract. Am $\mathcal{F}$ Surg $1971 ; 121: 174-83$.

7 Voitk AJ, Echave V, Feller JH, Brown RA, Gurd FN. Experience with an elemental diet in the treatment of inflammatory bowel disease. Is this primary therapy? Arch Surg 1973;107:329-33.

8 Rochio MA, Cha CJM, Haas KF, Randall HT. Use of chemically defined diets in the management of patients with acute inflammatory bowel disease. Am $\cdot \mathcal{F}$ Surg $1974 ; 127: 469-75$.
- Giorgini GL, Stephens RV, Thayer WR. The use of "medical by-pass" in the therapy of Crohn's disease: report of a case. Am F Dig Dis 1973; 18:153-7.

${ }^{10}$ Goode A, Hawkins ST, Feggetter JG, Johnston ID. Use of an elemental diet for long term nutritional support in Crohn's disease. Lancet 1976; i:122-4.

11 Segal AW, Levi AJ, Loewi G. Levamisole in the treatment of Crohn's disease. Lancet 1977 ;ii :382-4.

12 Tanner JM, Whitehouse RH, Marshall WA, Carter BS. Prediction of adult height from height, bone age, and occurrence of menarche, at ages 4 to 16 with allowance for midparent height. Arch Dis Child $1975 ; 50: 14-26$.

13 Wensenck F. Faecal flora of Crohn's patients. Serological differentiation between Crohn's disease and ulcerative colitis. In: Weterman IT, Pena AS, Booth CC, eds. The management of Crohn's disease. Amsterdam : Excerpta Medica, 1976.

14 Winitz MR, Adams DA, Seedman PN, Davis PN, Jayko LG, Hamilton JA. Studies in metabolic nutrition employing chemically defined diets. II. Effects on gut microflora populations. Am f Clin Nutr 1970;23: 546-59.

${ }^{15}$ Attebery HR, Sutter VL, Finegold SM. Effect of a partially chemically defined diet on normal human fecal flora. Am $\mathcal{F}$ Clin Nutr $1972 ; 25$ : 1391-8.

16 Crowther JS, Drasar BS, Goddard P, Hill MJ, Johnson K. The effect of chemically defined diet on the faecal flora and faecal steroid concentration. Gut 1973;14:790-3.

17 Bounous G, Devroede GJ. Effects of an elemental diet on human faecal flora. Gastroenterology $1974 ; 66: 210-4$

18 Denman AM. Nature and diagnosis of food allergy. Proc Nutr Soc 1979; 38:391-402.

19 Falchuk KR, Isselbacher KJ. Circulating antibody to bovine albumin in ulcerative colitis and Crohn's disease-characterisation of the antibody response. Gastroenterology 1976;70:5-8.

${ }^{20}$ Aufses AH, Kreel I. Ileostomy for granulomatous colitis. Ann Surg $1971 ; 173: 91-6$.

${ }^{21}$ McArdle AH, Brown RA, Echave V, Rivilis J, Thompson AG. Alterations in gastric and pancreatic secretion induced by the feeding of an elemental diet. Arch Fr Mal App Dig 1972;61:115C.

(Accepted 22 September 1980)

\title{
Pituitary responsiveness to gonadotrophin-releasing and thyrotrophin-releasing hormones in children receiving phenobarbitone
}

\author{
ANTONIO MASALA, TULLIO MELONI, SERGIO ALAGNA, PIER P ROVASIO, \\ GRAZIELLA MELE, VANNINA FRANCA
}

\section{Summary and conclusions}

The effect of long-term treatment with phenobarbitone on pituitary responsiveness to gonadotrophin-releasing hormone and thyrotrophin-releasing hormone was studied in 20 boys being treated with the drug to prevent febrile convulsions. Baseline concentrations of luteinising and follicle-stimulating hormones were reduced as well as the responses of these hormones to stimulation with gonadotrophin-releasing hormone. Baseline prolactin concentrations were raised in comparison with those in

Istituto di Patologia Speciale Medica, University of Sassari, Italy ANTONIO MASALA, MD, assistant SERGIO ALAGNA, MD, assistant PIER P ROVASIO, MD, assistant

Clinica Pediatrica, University of Sassari

TULLIO MELONI, MD, professor of paediatrics GRAZIELLA MELE, MD, assistant

VANNINA FRANCA, MD, assistant normal children. The response of prolactin to thyrotrophin-releasing hormone, however, was impaired only in the children who had been receiving the drug for a long time. Phenobarbitone had no effect on the secretion of growth hormone.

Further studies should be carried out to ascertain how long these effects on pituitary function last after phenobarbitone is withdrawn and whether this interference with pituitary function modifies the child's subsequent development.

\section{Introduction}

Long-term treatment with anticonvulsants such as phenytoin and phenobarbitone is useful in preventing febrile convulsions in children. It is generally accepted that to be effective treatment with phenobarbitone should be continued for several months at doses ranging from 3 to $5 \mathrm{mg} / \mathrm{kg}$ body weight daily, even in children who have had only one febrile seizure. ${ }^{12}$ Several centrally acting drugs interfere with the function of the 